\title{
Assessment of biotechnological potential of phosphate solubilizing bacteria isolated from soils of Southern Kazakhstan
}

\author{
Rakhilya Aipova ${ }^{1 *}$, Svetlana A. Aitkeldiyeva ${ }^{1}$, Askar A. Kurmanbayev ${ }^{1}$, \\ Amangeldy K. Sadanov ${ }^{2}$, Olga B.Topalova ${ }^{3}$ \\ ${ }^{1}$ Institute of Microbiology and Virology, Almaty, Republic of Kazakhstan; *Corresponding Author: Rakhilya 73@mail.ru \\ ${ }^{2}$ Center of biological investigations, Almaty, Republic of Kazakhstan \\ ${ }^{3}$ Kazakh Nationality pedagogical university, Almaty, Republic of Kazakhstan
}

Received 22 March 2010; revised 25 May 2010; accepted 29 May 2010.

\begin{abstract}
Phosphorus $(P)$ is a vital plant nutrient, available to plant roots only in soluble forms that are in short supply in the soil. Adding phosphatebased fertilizers to increase agricultural yields is a widely used practice; however, the bioavailability of $P$ remains low due to chemical transformations of $P$ into insoluble forms. Thus, phosphate solubilizing bacteria (PSB) play an important role in reducing $P$ deficiency in soil. The goal of this study was to assess biotechnological potential of phosphate-solubilizing bacterial strains. In this study, phosphate solubilizing microorganisms (PSM) were isolated from different soil samples of Southern regions of Kazakhstan. The biological activity of PSM was studied based on their effect on the growth of wheat seeds. The different taxonomic genera of these PSM were identified: Arthrobacter spp., Aureobacterium spp., Azotobacter spp., Bacterium spp., Baccillus spp. Finally, phosphatesolubilizing activity of isolated strains of PSM was assessed.
\end{abstract}

Keywords: Soil; Phosphate Solubilizing Bacteria; Identification; Labile Phosphorus; Fertilizers;

Phosphate; Phosphorus

\section{INTRODUCTION}

Phosphorus (P) is the second most important plant nutrient after nitrogen. However, most Phosphorus in soil (up to $95-99 \%$ ) is part of insoluble compounds, which makes $\mathrm{P}$ unavailable for plant nutrition [1]. In order to increase crop yields, mineral phosphate fertilizers are regularly incorporated into the soil. However, immedi- ately after fertilizer application is done, most of the applied phosphorus transforms into an insoluble form [2]. As a result, most $\mathrm{P}$ in the soil is found in poorly soluble, highly stable forms with limited availability to plants. Only $5 \%$ or less of the total amount of $\mathrm{P}$ in soil is available for plant nutrition [3]. The vicious cycle continues as such low bioavailability of $P$ requires regular application of phosphate-based fertilizers [4].

According to assessments made by the experts from the U.S. Geological Survey and the International Association of Fertilizer Producers, the demand for fertilizers over the next 5 years will increase by $2.5-3 \%$ annually [5]. At such rate of phosphate consumption, all global phosphate resources would be exhausted within 100-125 years [5]. Taking into account the long-term increase in demand for $\mathrm{P}$ and phosphate production, peaking in 20 years, the importance of partial $\mathrm{P}$ recycling continues to grow. Recovering phosphates from livestock waste is one of the examples of reusing $\mathrm{P}$ for agriculture [5]. Other ways to control the wastage of phosphate resources include reducing P run-off into the oceans.

Considering the anticipated food production crisis as it relates to phosphate deficit in the future, efforts to study and apply microbiological phosphate solubilization processes are well justified. Phosphate solubilizing Microorganisms (PSM) play an important role in plant nutrition and growth promotion, especially when phosphate fertilizers are used extensively for long periods of time. It has been proven that agricultural application of PSM boosts crop yields [6]. On the other hand, soil activity depends on the activity of phosphate solubilizing bacteria [7].

P solubilization mechanisms include acid formation, chelating metal ions and exchange reactions. The most active among PSM are micromycetes of following genera: Aspergillus, Penicillium, Curvularia, and phos- 
phate-solubilizing yeast, which is more active in solubilizing phosphates than bacteria. However, since bacteria are more suitable for high-volume production of biotechnology products, the goal of our research was to assess biotechnological potential of phosphate-solubilizing bacterial strains, isolated over the course of our research.

\section{MATERIAL AND METHODS}

The subject of this research was to study microorganisms identified from the soils of Southern Kazakhstan. Soil samples were taken in accordance with the aseptic regulations and recommendations and were stored in sterile parchment paper bags [8].

Calcium orthophosphate-dissolving bacteria were identified in the Muromcev medium of the following composition (g/l): glucose-10.0, asparagines-1.0, $\mathrm{K}_{2} \mathrm{SO}_{4}-$ $0.2, \mathrm{MgSO}_{4}-0.2$, corn extract-0.02; agar-20.0, tap water, $\mathrm{pH}=6.8$, sterilized at $0.5 \mathrm{~atm}$. for 20 minutes. The salts were added in dry form, which provided gradual interaction with the medium over the course of sedimentation. The proportion of dissolving agent was 1.5 grams of $\mathrm{Ca}_{3}\left(\mathrm{PO}_{4}\right)_{2}$ per liter of liquid medium. Nistatin was introduced additionally to suppress the growth of micromycetes, in proportion 500000 units per $250 \mathrm{ml}$ of sterilized medium. Mediums prepared by this method were distributed in $25 \mathrm{ml}$ amounts per Petri dish. After cooling down, the agar medium was added the soil suspensions (in $10^{-4}-10^{-7}$ dilution) in $0.1 \mathrm{ml}$ volume amounts. Petri dishes with soil suspension on the surface were incubated at $28^{\circ} \mathrm{C}$ for $3-9$ days. We counted only colonies that had zones of calcium phosphate dissolution around them.

To evaluate phosphate solubilizing microorganisms' influence on seed germination, we used wheat seeds. Laboratory research was conducted according to the Schroth, Hancock method 1982 [9]. The surface of the seeds was sterilized with $10 \%$ sodium hypochloride solution for 20 minutes, after which the seeds were washed with $70 \%$ ethanol and triple sterile distilled water.

Cultures of microorganisms under the study were incubated in $250 \mathrm{ml}$ flasks, containing $100 \mathrm{ml}$ of medium for cultivation (beef extract broth) at $28^{\circ} \mathrm{C}$ until they reached steady stage of growth (titer is $1 \times 10^{6}$ cells $/ \mathrm{mL}$ ). Culture-containing liquid was obtained by centrifuging bacterial suspension for 10 minutes at 5000 RPM. Bacterial biomass sediment was washed three times with physiological saline solution, later diluted with sterile distilled water. We used $10 \mathrm{ml}$ of test subculture per 20 seeds for 2 hours in each seed treatment round.

In accordance with aseptic regulations, inoculated seeds were placed onto dampened filter paper in Petri dishes. For control specimens, we used seeds treated with sterile water and sterile medium used for bacteria cultivation. Incubation was done at $28^{\circ} \mathrm{C}$.

Phosphate solubilizing activity of bacterial strains was determined using the Novogrudsky medium [10]. We added $1 \%$ suspension of phosphate-solubilizing bacterial (PSB) strains into the flasks containing $100 \mathrm{ml}$ of medium, and incubated the flasks on the shake flask propagator for 14 days at 180 RPM. After 14 days, we calculated the amount of labile phosphorus in the cell culture liquid by colorimetric method using blue phosphorusmolybdenum complex [11].

The active mass concentration was converted into $\mathrm{PO}_{4}^{3-} \mathrm{mg} / \mathrm{L}$ format using the following formula:

$\mathrm{X}=(1000 \times \mathrm{a}) /(\mathrm{V} \times 1000) \mathrm{mkg} / \mathrm{L}=0.1 \times \mathrm{a}(\mathrm{mg} / \mathrm{L})$, where:

a-phosphate ion content in the sample, defined by calibration chart, mkg;

$\mathrm{V}$-aliquot of a sample, 10 cubic centimeters.

\section{RESULTS AND DISCUSSIONS}

The form or type of phosphorus compounds in soil depends on oxidation-reduction conditions of the medium. The main component of mineral phosphates is tricalcium phosphate (calcium orthophosphate). In all of the soil samples assessed in our study using Muromcev medium, we observed visible zones of phosphate dissolution (Figure 1).

Inoculation of plants seeds by active strains of microorganisms is often beneficial to their growth and development. Such effect can be defined by different mechanisms: by intensification of nitrogen fixation and phosphate solubilization, by production of physiologically active substances, by an increase in root absorption capacity, or by improved solubility of highly immobile compounds of plant nutrients [12].

Table 1 and Figure 2 illustrate the influence of phosphate solubilizing bacterial treatment on wheat seed germination. Our research demonstrates that applying PSB in seed treatment increases wheat germination capacity (see strains P3-P6) and stimulates root growth as observed in all specimens (P1-P6).

Strains that positively affected wheat seed germination were identified at the species level. Table 2 presents morphological and biochemical characteristics of studied strains.

Based on the obtained data on strain characteristics, phosphate-solubilizing bacterial strains were identified as follows: P1-Artrobacter sp., P3-Bacillus sp., P6-Bacterium sp., P8-Aureobacterium sp., Az 1-Azotobacter sp. In order to evaluate PSB strains' ability to mobilize phosphorus from insoluble soil phosphates, a 

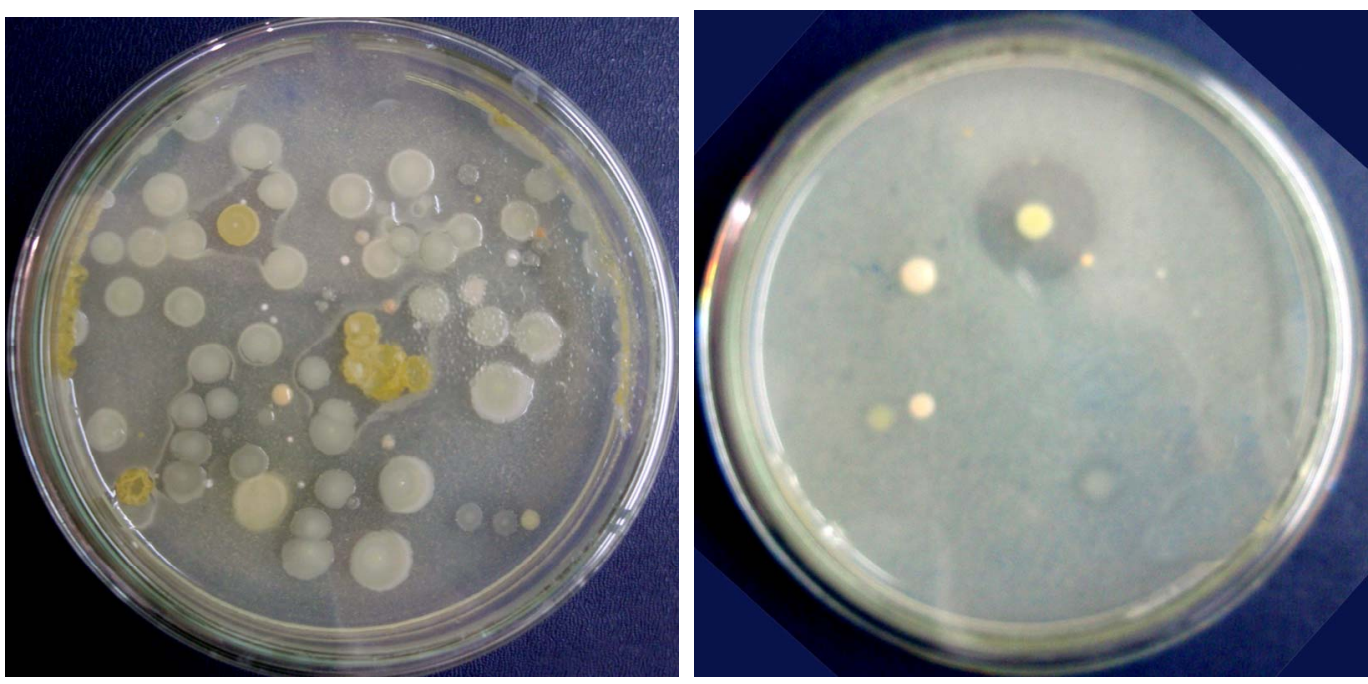

Figure 1. Phosphate dissolution zones around phosphate solubilizing bacteria colonies.
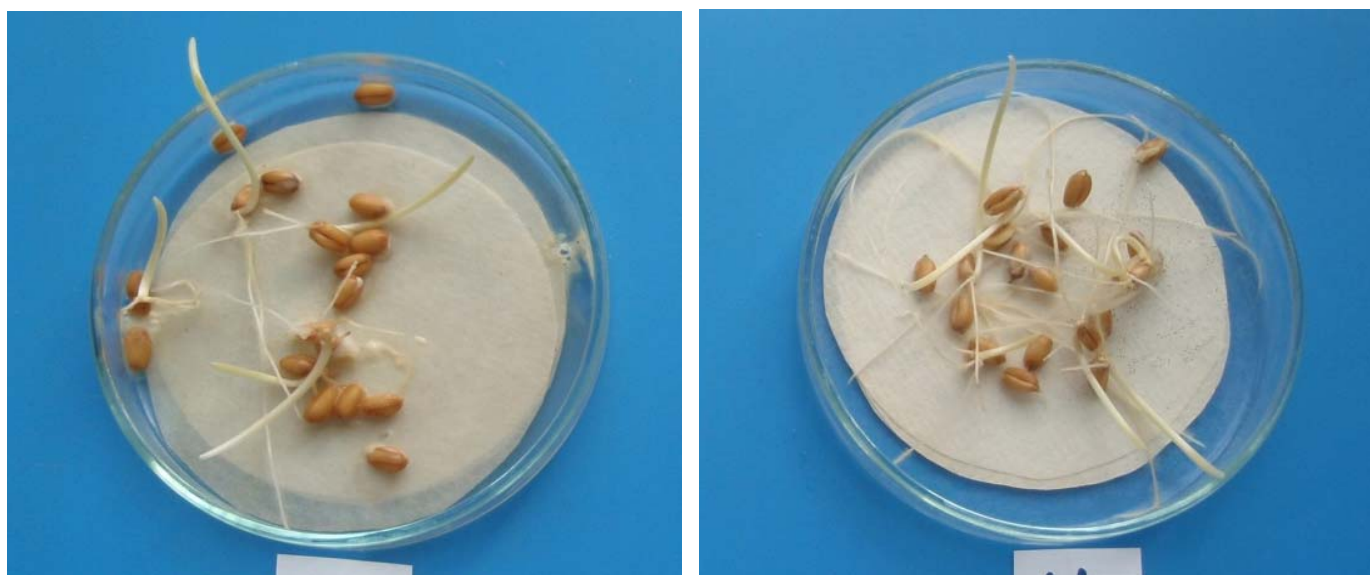

Figure 2. Germinated wheat seeds after treatment with PSB cell culture liquid. Left: control; Right: treatment with the P6 strain.

Table 1. The influence of phosphate solubilizing bacterial treatment on wheat seed germination.

\begin{tabular}{cccc}
\hline Strain of PSB & Germination capacity , \% & Average length of sprout, mm & Average length of root, mm \\
\hline Control & 65,00 & $40,69 \pm 5,02$ & $34,34 \pm 3,93$ \\
P1 & 46,65 & $32,40 \pm 3,03$ & $40,88 \pm 2,66$ \\
P2 & 61,65 & $43,25 \pm 9,84$ & $44,73 \pm 7,52$ \\
P3 & 66,65 & $29,40 \pm 8,79$ & $43,15 \pm 4,69$ \\
P4 & 68,35 & $20,63 \pm 7,94$ & $35,88 \pm 5,99$ \\
P5 & 76,65 & $24,58 \pm 17,55$ & $38,92 \pm 3,26$ \\
P6 & 66,65 & $32,76 \pm 0,23$ & $41,84 \pm 9,16$ \\
P7 & 51,65 & $23,29 \pm 8,12$ & $33,63 \pm 5,50$ \\
P8 & 60,00 & $25,79 \pm 11,77$ & $40,71 \pm 7,49$ \\
\hline
\end{tabular}

further experiment was conducted using strains P1, P3, P6, P8, Az1, which were grown over a 14-day period. In the obtained cell culture liquid, the assessment of soluble (labile) phosphorus concentration was done.
The assessment of phosphate solubilization activity by PSB strains (Table 3) has demonstrated that phosphorus mobilization activity has increased more than 100 times in comparison to control sample. The most active strains 
Table 2. Morphological, physiological, and biochemical characteristics of phosphate solubilizing bacteria strains in the study.

\begin{tabular}{|c|c|c|c|c|c|}
\hline \multirow{2}{*}{ Characteristics } & \multicolumn{5}{|c|}{ Strains } \\
\hline & $\mathbf{P}-1$ & $\mathbf{P}-\mathbf{3}$ & P-6 & P-8 & Az1 \\
\hline Morphology & rods & rods & rods & rods & rods \\
\hline Gram Staining & + & - & - & + & - \\
\hline Mobility & Immobile & Mobile & Mobile & Mobile & Mobile \\
\hline Acid-Fastness & - & + & - & - & \\
\hline Catalase & + & + & + & + & + \\
\hline Oxidase & + & + & + & - & \\
\hline Growth on Beef/Peptone Broth & + & + & + & + & \\
\hline Relationship with oxygen & P.anaerobe & P.anaerobe & P.anaerobe & Aerobes & Aerobes \\
\hline Dilution of gelatin & + & + & - & + & \\
\hline Hydrogen sulphide formation & - & + & - & + & \\
\hline Nitrate formation & - & + & + & - & \\
\hline Starch Hydrolysis & + & - & - & - & + \\
\hline Indole formation & - & + & - & - & \\
\hline Ammonia formation & + & - & - & - & \\
\hline Spore formation & - & + & - & - & - \\
\hline \multicolumn{6}{|l|}{$\begin{array}{l}\text { Growth on Beef/Peptone Broth } \\
\text { with } \mathrm{NaCl}\end{array}$} \\
\hline $3 \%$ & + & + & + & + & \\
\hline $6 \%$ & + & + & + & + & \\
\hline Starch conversion & + & - & - & - & + \\
\hline \multicolumn{6}{|c|}{ Carbohydrate uptake: } \\
\hline Glucose & A & $\mathrm{AG}$ & $\mathrm{A}$ & $\mathrm{A}$ & \\
\hline Galactose & As & $\mathrm{AG}$ & $\mathrm{AG}$ & As & \\
\hline Glucose & $\mathrm{A}$ & $\mathrm{AG}$ & A & $\mathrm{A}$ & \\
\hline Xylose & As & $\mathrm{AG}$ & A & As & \\
\hline Lactose & As & $\mathrm{AG}$ & A & As & \\
\hline Fructose & A & $\mathrm{AG}$ & A & A & \\
\hline Arabinose & A & AG & A & As & \\
\hline Saccharose & A & $\mathrm{AG}$ & $\mathrm{A}$ & A & \\
\hline Maltose & $\mathrm{A}$ & $\mathrm{AG}$ & As & A & \\
\hline Glycerin & As & $\mathrm{AG}$ & As & As & \\
\hline Mannitol & A & $\mathrm{AG}$ & As & As & \\
\hline \multicolumn{6}{|c|}{ Growth under different temperatures } \\
\hline$-3^{\circ} \mathrm{C}$ & + & - & + & + & \\
\hline $22^{\circ} \mathrm{C}$ & + & + & + & + & + \\
\hline $28^{\circ} \mathrm{C}$ & + & + & + & + & \\
\hline $30^{\circ} \mathrm{C}$ & + & + & + & + & + \\
\hline $37^{\circ} \mathrm{C}$ & + & + & - & + & \\
\hline \multicolumn{6}{|c|}{ Comment: As-assimilates, A-acid formation, AG-acid and gas formation } \\
\hline
\end{tabular}

Table 3. Phosphate solubilization activity with the following PSB strains.

\begin{tabular}{cc}
\hline Strains: & $\begin{array}{c}\text { Concentration of } \mathrm{P}_{2} \mathrm{O}_{5} \text { in mkg per } 1000 \mathrm{ml} \text { of } \\
\text { medium/phosphate mobilization }\end{array}$ \\
\hline P8 & $75000 / 0,008$ \\
P1 & $70000 / 0,007$ \\
P3 & $44000 / 0,004$ \\
P6 & $20000 / 0,002$ \\
Az 1 & $47300 / 0,005$ \\
P1 + P8 & $146000 / 0,015$ \\
Az 1 & $800 / 0,00008$ \\
Control & \\
\hline
\end{tabular}

were P8, P1 and Az1 strains, whereas strain P6 was least active. Growing three strains simultaneously (P1 + P8 + Az 1) allowed the highest level of phosphorus mobilization.

\section{CONCLUSIONS}

The results obtained over the course of this study let us theorize that phosphate solubilizing bacteria positively affect wheat seed germination in a multifaceted way. Identification of PSB in our study has demonstrated that 
they belong to different taxonomic bacterial genera: Azotobacter sp., Artrobacter sp., Bacterium sp., Bacillus $s p$., and Aerobacterium sp. We believe that the strains obtained in samples P8, P1 and Az 1 are of particular interest for further research.

\section{REFERENCES}

[1] Corona, M.E.P., Klundert, I.V.D. and Verhoeven, J.T.A. (1996) Availability of organic and inorganic phosphorus compounds as phosphorus sources for carex species. New Phytologist, 133(2), 225-231.

[2] Pundarikakshudu, R. (1989) Studies of the phosphate dynamics in a vertisol in relation to the yield and nutrient uptake of rainfed cotton. Experimental Agriculture, 25(4), 39-45.

[3] Boronin, A.M. (1998) Rhizosphere bacteria of the genus Pseudomonas enabling plant growth and development. Sorovsky Educational Magazine, 10, 25-31.

[4] Omar, S.A. (1998) The role of rock-phosphate-solubilizing fungi and vesicular-arbusular-mycorrhiza (VAM) in growth of wheat plants fertilized with rock phosphate. World Journal of Microbiology and Biotechnology, 14(2), 211-218.

[5] Gilbert, N. (2009) Environment: The disappearing nutri- ent. Nature, 461(7265), 716-718.

[6] Khan, M.S., Zaidi, A. and Wani, P.A. (2007) Role of phosphate-solubilizing microorganisms in sustainable agriculture-A review. Agronomy for Sustainable Development, 27(1), 29-43.

[7] Rimkevich, O.V. (2006) Environmental and functional roles of microorganisms in technogenically disturbed soils (based on samples from Dambukinsk gold-mining site). Dissertation Thesis for Ph.D. Degree, Blagoveshensk.

[8] Tepper, E.Z., Shilnikova, V.K. and Pereverzeva, G.I. (2004) Microbiology practicum: Study aid for universities. Drofa, Moscow.

[9] Schroth, M.N. and Hancock, J.G. (1982) Disease-suppressive soil and root-colonizing bacteria. Science, 216(4553), 1376-1381.

[10] Rodina, A.G. (1965) Aquatic microbiology methods. Nauka, Moscow; Leningrad.

[11] Namsaraev, B.B., Barkhutova, D.D. and Khakhinov, V.V. (2006) Field practicum in aquatic microbiology and aquatic chemistry. Ulan-Ude.

[12] Gromovyh, T.I., Litovka, Y.A., Sadykova, V.S. and Gabdulina, И.G.-M. (2005) Perspective for applicationincrop science/biological features of a new strain of streptomyces lateritius 19/97-M, promising for use in crop science. Biotechnology, 5, 37-40. 